УДК 504.03:796.5(571.6)

ЭКОЛОГИЧЕСКИЙ АСПЕКТ РАЗВИТИЯ ТУРИЗМА НА ПРИБРЕЖНЫХ ТЕРРИТОРИЯХ РОССИЙСКОГО ДАЛЬНЕГО ВОСТОКА

\author{
Степанько Н.Г.
}

ФГБУН «Тихоокеанский институт географии ДВО РАН», Владивосток, e-mail: sngreg25@таil.ru

\begin{abstract}
В современных условиях как российский, так и мировой рынок туристских услуг претерпевает существенные изменения, а также увеличение нерешенных проблем. Безусловно, сложившиеся проблемы мирового туризма из-за пандемии вызвали активизацию внутреннего туризма в России. Регионы Российского Дальнего Востока (РДВ) являются привлекательными не только своим минерально-сырьевым потенциалом, но и природными ресурсами туристско-рекреационной направленности. Но хозяйственная деятельность, направленная на добычу и переработку минерального сырья, сформировала неблагоприятную экологическую ситуацию в ряде регионов РДВ. И это является существенным ограничением развития индустрии туризма, который перспективен и более приемлем с точки зрения сбалансированности эколого-экономических отношений. Анализ эколого-экономической ситуации в Чукотском АО, Камчатском и Приморском краях, Сахалинской области, как регионах, наиболее привлекательных и перспективных для развития туризма, является необходимым и своевременным, что и явилось целью данного исследования. На основе информационной базы Росстата, а также методических подходов и расчетов автора проведенное исследование позволило получить картину возможной экологической ситуации в рассматриваемых регионах, учитывая ситуацию сегодняшнего дня, и возможную при условии реализации основных инвестиционных проектов в выделенных регионах. В работе представлен анализ хозяйственной деятельности в рассматриваемых регионах Тихоокеанской России и основных инвестиционных проектов, а также оценка направлений природопользования. Автором предложен и рассчитан индекс экономической достаточности (ИЭД) природоохранной деятельности. Он позволяет оценить современную эколого-экономическую ситуацию и возможность развития туристско-рекреационной деятельности в регионах РДВ.
\end{abstract}

Ключевые слова: Тихоокеанская Россия, туризм, экологическое состояние, структура природопользования индекс экономической достаточности, эколого-экономическая сб̆алансированность.

\title{
ENVIRONMENTAL ASPECT OF TOURISM DEVELOPMENT IN THE COASTAL TERRITORIES OF THE RUSSIAN FAR EAST
}

\section{Stepanko N.G. \\ Pacific Institute of Geography Far Eastern Branch of Russian Academy of Sciences, Vladivostok, e-mail: sngreg25@mail.ru}

In modern conditions, both the Russian and the world market of tourist services is undergoing significant changes. Of course, the existing problems of world tourism due to the pandemic have caused an intensification of domestic tourism in Russia. The regions of the Russian Far East (RFE) are attractive as heir mineral and raw material potential, so for their natural resources for tourism. Economic activities aimed at the extraction and processing of mineral raw materials have formed an unfavorable environmental situation. This is a significant limitation of the development of the tourism industry, which is promising and more acceptable from the point of view of the balance of environmental and economic relations in this territory. Analysis of the ecological and economic situation in the Chukotka Autonomous Okrug, Kamchatka and Primorsky Territories, the Sakhalin Region, as the most attractive and promising regions for tourism development, is necessary and timely, which was the purpose of this study. Based on the information base of Rosstat, as well as the methodological approaches and calculations of the author, the study made it possible to obtain a picture of the possible environmental situation in the regions under consideration, taking into account the current situation and possible subject to the implementation of the main investment projects in the selected regions. The paper presents an analysis of economic activity in the considered regions of Pacific Russia and the main investment projects, as well as an assessment of the areas of environmental management, The author proposed and calculated the economic sufficiency index (ESI) of environmental protection activities. It possible to assess the current ecological and economic situation and the possibility of developing tourist and recreational activities in the regions of the RFE.

Keywords: Pacific Russia, tourism, ecological state, nature management structure, economic sufficiency index, ecological and economic balance

В настоящее время регионы Российского Дальнего Востока привлекают отечественных и зарубежных инвесторов, исследователей, туристов своим разнообразием природных ресурсов и с точки зрения добычи и переработки сырьевых ресурсов, а также как объекты отдыха, оздоровления, путешествий. Особенно это касается прибрежных территорий Тихоокеанской России: Чукотского АО, Камчатского и Приморского краев, Сахалинской области. Эти регионы неравнозначны по природно-климатическим условиям, социально-экономическому развитию, демографической ситуации, развитию туристской инфраструктуры. Но все они уникальны по своим природным условиям и ресурсам и являются основой развития туристского вида деятельности в рассматриваемых регионах.

Развитие такой отрасли, как индустрия туризма и рекреации, напрямую зависит от экологии [1-3]. Исследуемые регионы 
в силу своего экономического развития дифференцированы по территориальной хозяйственной структуре, характеру и направлениям природопользования и, как следствие, экологическому состоянию. Изучение и анализ этой составляющей является актуальным для разработки стратегии развития перспективного для ряда регионов Тихоокеанской России туристического вида деятельности.

Цель исследования - анализ эколого-экономической ситуации в выделенных районах с учетом сложившейся ситуации и основных инвестиционных проектов, а также последствий их реализации для формирования модели развития туристической деятельности.

\section{Материалы и методы исследования}

Базовыми материалами для проведения исследования являются научные литературные источники, статистическая информация Росстата, а также приведены результаты расчетов автора.

Для оценки эколого-экономической ситуации была использована официальная статистическая база Росстата: «Основные показатели охраны окружающей среды», статистические бюллетени, «Регионы России. Социально-экономические показатели» исследуемых регионов. Поскольку решение вопросов и проблем охраны природы и рационального природопользования зависит от финансового обеспечения последних, проведен расчет по методике автора индекса экономической достаточности (ИЭД), предложенный ранее [4], который представляет собой соотношение фактического объема финансирования охраны окружающей среды и экономического оптимума, предложенного Колесниковым С.И. [5]. Проведенные ранее расчеты ИЭД для регионов Российского Дальнего Востока [6] показали объективность предложенного показателя и соответствие действительно существующего дисбаланса в эколого-экономическом отношении.

\section{Результаты исследования и их обсуждение}

Уникальная природа, разнообразие ресурсов, история и культура коренных народов, имеющиеся оздоровительные комплексы создают все условия для успешного развития практически во всех регионах Российского Дальнего Востока индустрии туризма и отдыха. Однако в результате деятельности человека в настоящее время по многим показателям наблюдается существенное ухудшение состояния окружающей природной среды: снизилась лесистость, продуктивность, видовой состав лесов, многие реки в исследуемых регионах перешли в категорию «грязных», продолжается сброс неочищенных сточных вод, наблюдается превышение ПДК в атмосферных выбросах и т.д. и, как следствие, усиливается экологоэкономический дисбаланс. В формирование экологического состояния регионов основной негативный «вклад» вносят атмосферные выбросы и сброс загрязненных сточных вод, что характерно для всех регионов РДВ.

Экономика регионов Российского Дальнего Востока (РДВ) в целом, и в том числе Чукотского АO, Камчатского и Приморского краев, Сахалинской области, имеет ресурсную направленность. Эти территории обладают около 30\% ресурсного потенциала России: руды черных и цветных металлов, драгоценные металлы и алмазы, нефть, уголь, газ, химическое сырье, лесные ресурсы и др. Соответственно, разнообразно и природопользование, производственно-природные отношения, складывающиеся между хозяйственными предприятиями и природно-ресурсной средой. Экологическое состояние территории формируют существующие типы природопользования (как по линии извлечения, потребления и использования ресурсной базы, так и по линии выведения отходов), его структурные направления и природоохранная деятельность. Анализ эколого-экономической информации о хозяйственной деятельности в рассматриваемых регионах Тихоокеанской России, а также основных инвестиционных проектов позволил провести оценку направлений природопользования (балльная качественная оценка, условно принятая от + до +++++) (таблица). Трансформационные процессы, предполагаемые при реализации основных инвестиционных проектов, названы как «возможные».

Перспективы развития хозяйственных структур регионов Тихоокеанской России связаны в основном с добывающими отраслями, т.к. основные проекты связаны с освоением природно-ресурсного потенциала (прибрежная зона + шельф), планируется развитие таких видов хозяйственной деятельности, как угледобыча, энергетика, горная добыча и переработка (ГОК, ГМК), металлургия, судоремонт, усилится газодобыча и переработка (СПГ), реконструкция портов, строительство портопунктов и перегрузочных терминалов, туризм. Это направление развития повлечет за собой изменения и в пространственно увязывающем структурном направлении, а также отчасти в коммунальном (таблица). 
Безусловно, такое развитие может привести к экономическому подъему в регионах, но, учитывая существующую экологическую ситуацию и практически отсутствие действенных мер в области природоохранной деятельности, а также отсутствие превентивных мер (например, ввод необходимых современных для конкретного вида деятельности методов очистки, утилизации, рекультивации и т.д.), усугубится дисбаланс в эколого-экономических отношениях, экологическая ситуация ухудшится, что может стать препятствием для развития индустрии туризма $[8 ; 9]$.

Кроме воздействий хозяйственной деятельности, эффективность природополь- зования и, как следствие, экологическую ситуацию формирует и существующая в регионе природоохранная деятельность. Проведенный анализ показал, что увеличение инвестиций в основной капитал в регионах Дальнего Востока, рост валового регионального продукта (ВРП) не влечет за собой увеличения финансирования природоохранной деятельности (например, рис. 1). Экологический оптимум [5] финансирования не отмечен ни в одном регионе РДВ (рис. 2). Индекс экономической достаточности (ИЭД) [4] (находится из соотношения суммы всех затрат на ООС и экономического оптимума природоохранных затрат - 8\% от ВРП [5]) не достигает даже нижнего предела (2\%).

Трансформация природопользования, 2005/2017 гг./возможные

\begin{tabular}{|c|c|c|c|c|}
\hline $\begin{array}{c}\text { Структурные направления } \\
\text { природопользования [7] }\end{array}$ & $\begin{array}{c}\text { Камчатский } \\
\text { край }\end{array}$ & $\begin{array}{c}\text { Приморский } \\
\text { край }\end{array}$ & $\begin{array}{c}\text { Сахалинская } \\
\text { область }\end{array}$ & Чукотский АО \\
\hline Производственное & $\begin{array}{c}+++1++/ \\
+1++\end{array}$ & $++1+1$ & $\begin{array}{c}+++/++1 \\
+++++\end{array}$ & $\begin{array}{c}++1++1 \\
+++\end{array}$ \\
\hline Пространственно увязывающее & $++/+/++$ & $\begin{array}{c}++/+1+1 / \\
+1+\end{array}$ & $\begin{array}{c}++/+H+1 \\
+H+\end{array}$ & $+/+/++$ \\
\hline Коммунальное & $++/++/++$ & $++/+++/$ & $\begin{array}{c}++/++/ \\
+++\end{array}$ & $+/+/+$ \\
\hline Средоохранное & $+/++/-$ & $++/+++/-$ & $++/+++/-$ & $+/++/-$ \\
\hline
\end{tabular}

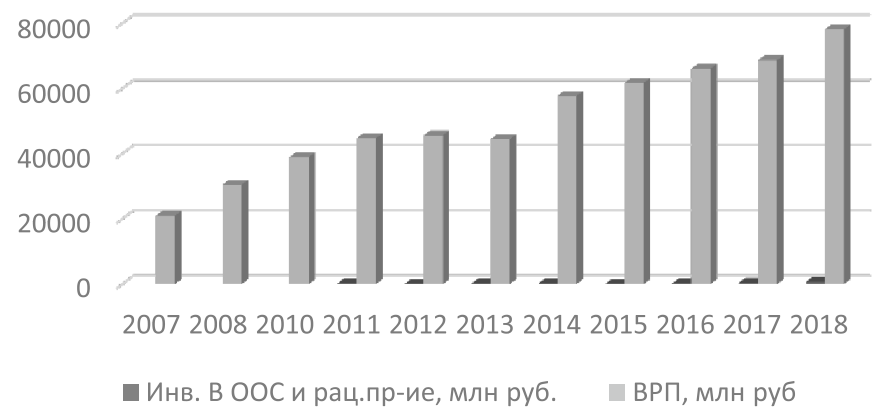

Рис. 1. Динамика соотношения ВРП и инвестиций на ООС в Чукотском АО

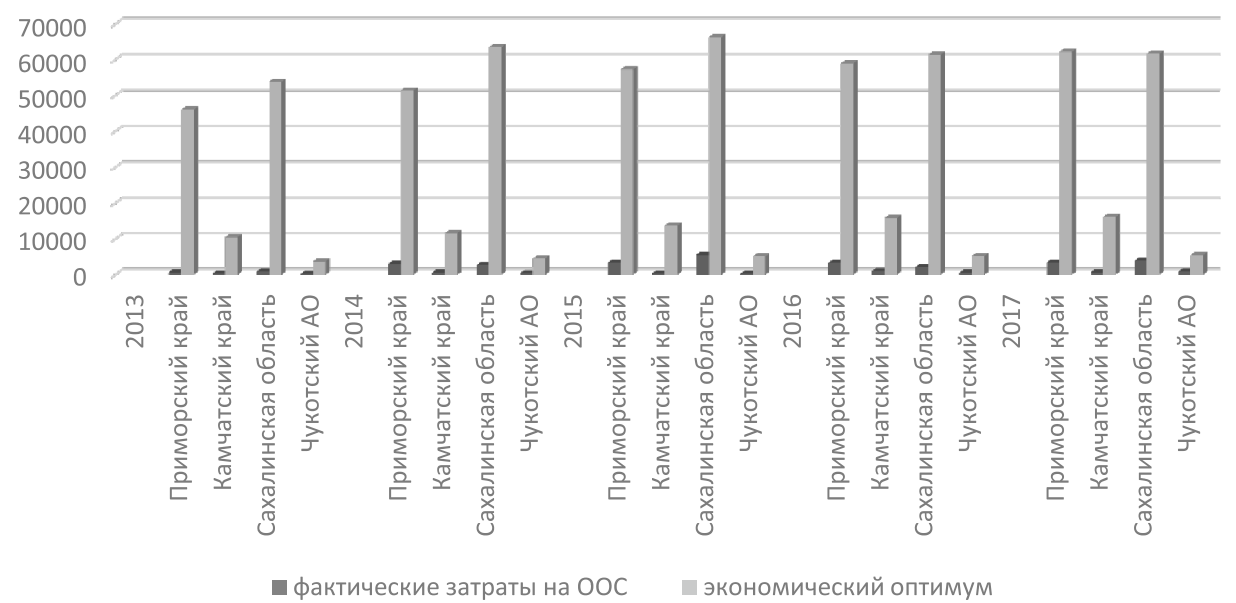

Pис. 2. Соотношение фактических и необходимых затрат на ООС 


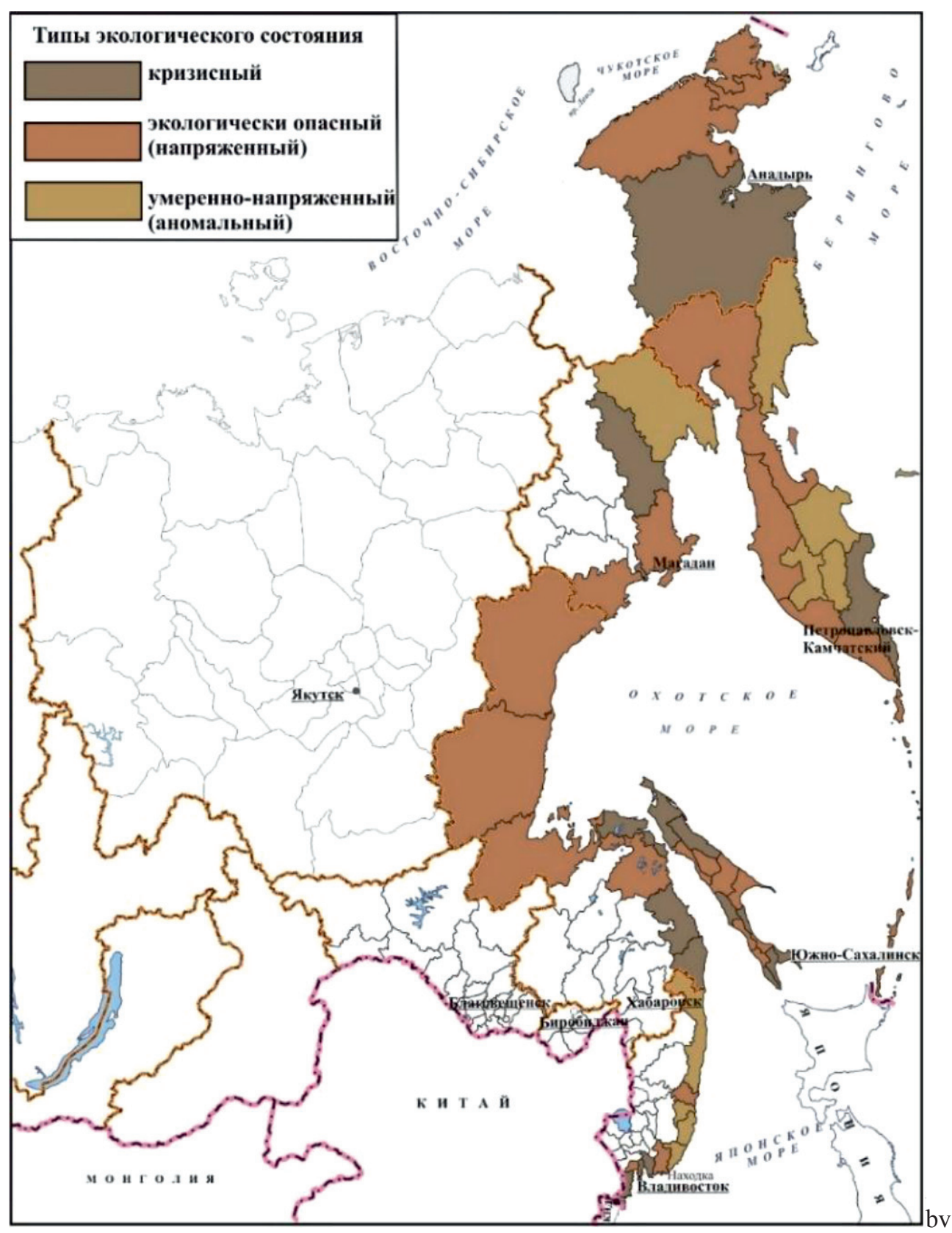

Рис. 3. Типология прибрежных территорий регионов Тихоокеанской России по экологическому состоянию (возможный вариант)

На основе ранжированных величин суммарного загрязнения (загрязненные атмосферные выбросы и сброс загрязненных сточных вод) [6], структуры имеющихся и возможных в перспективе производств соответствующих классов вредности проведена типология рассматриваемой территории по предполагаемому экологическому состоянию в разрезе административных районов. Поскольку в документах по перспективам развития регионов, и в т.ч. отдельных му- ниципальных районов, практически нет информации предполагаемых объемов производства, учитывался только класс вредности конкретных производств (как существующих, так и планируемых) и существующая экологическая ситуация (рис. 3). Все муниципальные районы и ГО рассмотренных территорий сгруппировались в три типа:

кризисный тип - характеризуется приближением параметров состояния окружающей среды в результате антропогенного 
воздействия к допустимым пределам изменений, переход через которые влечет за собой потерю устойчивости системы, а в дальнейшем ее разрушение;

экологически опасный тип - состояние, при котором скорость антропогенных нарушений превышает темп самовосстановления природных систем, но еще не происходит коренного их изменения или происходит пока обратимая замена прежде существовавших экологических систем на менее продуктивные;

умеренно напряженный тип - состояние среды, при котором один или несколько параметров состояния среды достигают величин, существенно отличающихся от фоновых характеристик данной местности, или нарушаются некоторые свойства окружающей среды. В аномальном состоянии окружающая среда не теряет еще своей системной целостности, но приобретает характеристики экологически несбалансированной системы и может оказать вредное воздействие на человека либо не удовлетворять его потребности [10].

\section{Заключение}

Помимо разнообразных природных рекреационно-туристических ресурсов, в рассматриваемых регионах значительна как по запасам, так и по разнообразию минерально-сырьевая база, освоение которой остается приоритетным направлением развития этих территорий. А это значит, что в структурных направлениях как современного, так и перспективного природопользования будет преобладать производственное направление, которое усилится в результате реализации основных инвестиционных проектов с четкой ориентацией на добывающие отрасли.

Дальнейшее освоение ресурсного потенциала минерально-сырьевого комплекса, создание новых производств, формирование инфраструктурных звеньев, безусловно, будет способствовать улучшению социальноэкономической ситуации на исследуемой территории. Но в то же время ухудшение экологической ситуации станет значимым ограничением развития индустрии туризма и рекреации.

Выявлено, что рассмотренные территории, несмотря на более благоприятное экологическое состояние по сравнению с территориями западной части России, имеют существенные негативные последствия техногенного воздействия. При реализации инвестиционных проектов, на- правленных на дальнейшее использование природно-ресурсного потенциала, как наиболее приоритетного, усилится дисбаланс в эколого-экономических отношениях, усилится техногенный прессинг и, как следствие, ухудшится экологическое состояние, что скажется на условиях жизнедеятельности, отдыха и оздоровления населения.

Предложенная типология наиболее привлекательных с точки зрения развития туризма и рекреации прибрежных территорий рассматриваемых регионов Тихоокеанской России по экологическому состоянию выявила преобладание экологически опасного или напряженного типа, т.е. состояния, при котором скорость антропогенных нарушений превышает темп самовосстановления природных систем, но еще не происходит коренного их изменения. Наиболее благоприятная ситуация наблюдается в Приморском крае за исключением южных районов, которые в границах Приморья являются наиболее привлекательными с точки зрения развития туризма.

В каждом рассмотренном субъекте имеются такие муниципальные образования (MO), где возможно значительное ухудшение экологической ситуации. Эти МО относятся к кризисному типу, при котором параметры состояния окружающей среды в результате антропогенного воздействия приблизятся к пороговым показателям, переход через них повлечет за собой потерю устойчивости системы, а в дальнейшем ее разрушение.

При определении направлений развития территориальных природно-хозяйственных структур во главе угла должно быть сбалансированное эколого-экономическое развитие этих территорий с учетом всестороннего анализа экономической необходимости и экологической допустимости освоения, добычи и переработки минерально-сырьевых ресурсов, рассмотрения альтернативных перспективных направлений видов деятельности, к которым относится индустрия туризма и для которых имеется необходимая ресурсная база, а также активное внедрение принципов «зеленой экономики».

Исследование выполнено в рамках государственного задания Минобрнауки РФ (№ AAAA-A16-116110810013-5) при финансовой поддержке РФФИ (№ 20-55-18010).

\section{Список литературы / References}

1. Васильева И.О., Муратова М.Н. Развитие туризма в Арктике // Международный научно-исследовательский журнал. 2016. С. 78-83. 
Vasilyeva I.O., Muratova M.N. Tourism development in the Arctic // Mezhdunarodnyj nauchno-issledovatelskij zhurnal. 2016. P. 78-83 (in Russian).

2. Захаров Л.Н., Игнатьев А.А. Опыт Финляндии в области развития индустрии туризма // Российский Внешнеэкономический вестник. 2013. № 1. С. 28-41.

Zakharov L.N., Ignatiev A.A. The experience of Finland in the development of the tourism industry // Rossijskij Vneshnejekonomicheskij vestnik. 2013. No. 1. P. 28-41 (in Russian).

3. Kajan E. Arctic Tourism and Sustainable Adaptation: Community Perspectives to Vulnerability and Climate Change. Scandinavian journal of hospitality and tourism. 2014. Vol. 14. Issue 1. P. 60-79.

4. Степанько Н.Г. Методические подходы к оценке экологичности природопользования // Труды ТГУ. Серия геолого-географическая. Томск: ТГУ, 2012. С. 239-242.

Stepanko N.G. Methodical approaches to assessing the environmental friendliness of natural resources // Trudy TGU. Serija geologo-geograficheskaja. Tomsk: TSU, 2012. P. 239242 (in Russian).

5. Колесников С.И. Экономика природопользования: учебно-методическое пособие. Ростов н/Д., 2000. С. 14-15.

Kolesnikov S.I. Environmental economics: study guide. Rostov n/D., 2000. P.14-15 (in Russian).

6. Степанько Н.Г., Мошков А.В. Природно-ресурсные и экологические факторы в развитии территориальных хозяйственных структур // Геосистемы Дальнего Востока России на рубеже XX-XXI веков. Территориальные социально- экономические структуры. Владивосток: Дальнаука, 2012. T. III. C. 99-111.

Stepanko N.G., Moshkov A.V. Natural resource and environmental factors in the development of territorial economic structures // Geosistemy Dalnego Vostoka Rossii na rubezhe XXXXI vekov. Territorialnye socialno-jekonomicheskie struktury. Vladivostok: Dalnauka, 2012. Vol. III. P. 99-111 (in Russian).

7. Соколов Э.М., Захаров Е.И., Волков А.В., Панферова И.В., Чаплыгин Н.Н. Природопользование. Учебное пособие для ВУЗов. М. Тула: ИПП «Гриф и К», 2002. 522 с.

Sokolov E.M., Zakharov E.I., Volkov A.V., Panferova I.V., Chaplygin N.N. Nature management. Textbook for universities. M. Tula: IPP «Grif and $\mathrm{K}^{0} », 2002.522$ p. (in Russian).

8. Davies W., Van Alstine, Lovett J. C. 'Frame Conflicts' in Natural Resource Use: Exploring Framings Around Arctic Offshore Petroleum Using Q-Methodology. Environmental Policy and Governance. 2015. Vol. 26. Issue 6. P. 482-497.

9. Ecology of Murmansk. [Electronic resource]. URL: http://ekovolga.com/nashi-goroda/760-ekologiya-murmanska. html (date of access: 27.07.2021).

10. Степанько Н.Г., Ткаченко Г.Г. Перспективы экологоэкономической ситуации на прибрежной территории Тихоокеанской России // МЭЖ. 2021. № 1. [Электронный ресурс]. URL: https://qje.su/nauki-o-zemle/moskovskij-ekonomicheskijzhurnal-1-2021-54/ (дата обращения: 27.07.2021).

Stepanko N.G., Tkachenko G.G. Prospects for the ecological and economic situation in the coastal territory of Pacific Russia // MEJ. 2021. № 1. [Electronic resource]. URL: https://qje.su/nauki-o-zemle/moskovskij-ekonomicheskijzhurnal-1-2021-54/ (date of access: 27.07.2021) (in Russian) 